\title{
Comparison of renal morphology in the Streptozotocin and the SHR/N-cp models of diabetes
}

\author{
ML Gross ${ }^{1}$, E Ritz $^{2, *}$, A Schoof ${ }^{1}$, M Adamczak ${ }^{2,3, *}$, A Koch ${ }^{1}$, O Tulp ${ }^{4}$, A Parkman ${ }^{5}$, \\ A El-Shakmak ${ }^{6}$ A Szabo ${ }^{6}$ and K Amann ${ }^{7}$ \\ ${ }^{1}$ Department of Pathology, University of Heidelberg, Im Neuenheimer Feld 220/221, Heidelberg, Germany; \\ ${ }^{2}$ Department of Internal Medicine, University of Heidelberg, Germany; ${ }^{3}$ Department of Nephrology, \\ Endocrinology and Metabolic Diseases, Medical University of Silesia, Katowice, Poland; ${ }^{4}$ London College of \\ Medicine, Technology and Research, 37 Store Street, Ste 654, Bloomsbury, London, UK; ${ }^{5}$ Department of \\ Bioscience and Biotechnology, Drexel University, 32nd and Chestnut Streets, Philadelphia, Pennsylvania, \\ USA; ${ }^{6}$ Pediatric Nephrology Semmelweiß University Budapest, Hungary and ${ }^{7}$ Department of Pathology, \\ University of Erlangen, Krankenhausstrasse 8-10, Erlangen, Germany
}

\begin{abstract}
The Streptozotocin (STZ) model of diabetes is commonly used for studies of diabetic nephropathy although the histological lesions of the kidney are mild and do not resemble those seen in diabetic patients. The SHR/N-cp rat model of type II diabetes spontaneously develops pronounced abnormalities in renal histology. In the present study, we compared renal morphology in the STZ rat and the diabetic SHR/N-cp rat. Sprague-Dawley rats received STZ, developed diabetes after 2 days and were treated with insulin. In the SHR/N-cp rat, obesity is inherited as an autosomal recessive trait. The progeny are either lean (used as controls) or obese and diabetic. After 6 months of observation, STZ and SHR/N-cp rats were killed. The renal damage was evaluated by assessing damage indices and by using stereological techniques. In addition, immunohistochemistry and electron microscopy were performed. The glomerular and tubulointerstitial changes were much more pronounced in the diabetic SHR/N-cp compared to the STZ model. In parallel glomerular PCNA + cells were significantly more frequent and expression of TGF- $\beta$ and PDGF by immunohistochemistry in glomeruli and in the tubulointerstitial space was more pronounced in SHR/N-cp compared to STZ rats. The glomeruli of SHR/N$\mathrm{cp}$ contained less and larger podocytes as well as smaller mesangial cells embedded in more mesangial matrix compared to STZ. Similarly, less, but larger endothelial cells were found in SHR/N-cp than in STZ rats. The mean glomerular volume was similarly increased in the two models. Albumin excretion was only modestly increased in STZ diabetes, but pronounced in the SHR/N-cp rat. Although the STZ model of diabetes exhibits numerous biochemical sequelae of hyperglycemia, the morphological lesions are unimpressive. In contrast, the diabetic SHR/N-cp exhibits marked structural lesions, particularly podocyte damage and mesangial expansion that promise to make it a more suitable model for investigation of diabetic glomerulosclerosis.

Laboratory Investigation (2004) 84, 452-464, advance online publication, 19 January 2004;doi:10.1038/labinvest.3700052
\end{abstract}

Keywords: diabetic nephropathy; animal model; morphology

Diabetic nephropathy, mainly type II diabetes is the leading cause of end-stage renal disease in Western countries. ${ }^{1}$ Type II, that is, noninsulin-dependent diabetes mellitus, is far from being a well-defined

Correspondence: Dr M-L Gross, Department of Pathology, University of Heidelberg, Im Neuenheimer Feld 220/221, 69120 Heidelberg, Germany.

E-mail: Marie-Luise_Gross@med.uni-heidelberg.de

*Also at: Department of Internal Medicine, University of Heidelberg, Bergheimerstr. 58, Heidelberg, Germany

Received 31 July 2003; revised 27 November 2003; accepted 04 December 2003; published online 19 January 2004 disorder. It represents various metabolic derangements with a single common feature: inappropriate chronic hyperglycemia and glucose intolerance. ${ }^{2}$ Although many patients with type II diabetes and microalbuminuria have the classic morphology of the Kimmelstiel-Wilson type, a sizeable proportion exhibits vascular and interstitial lesions with minimal glomerular changes or none at all. ${ }^{3}$ Increased glomerular volume predicts the development of overt nephropathy in type I diabetes. In contrast, higher glomerular volume was found in type II diabetes by some, ${ }^{4}$ but not all authors. $^{5}$ 
Until now, most studies investigating the pathogenesis of diabetic nephropathy have used the STZ model. A number of pathological features such as activation of protein kinase $\mathrm{C}^{6}{ }^{6}$ deposition of advanced glycation end products (AGE), ${ }^{7}$ mesangial cell activation ${ }^{8}$ and podocyte injury ${ }^{9}$ have been described in this model, but even after long-term follow-up morphological lesions of the glomerulus remain modest at best, underlining the need for additional models.

Although more severe injury may be generated in animals by superimposition of hypertension, ${ }^{10}$ selection of specific genetic backgrounds or genetic modulation of signaling pathways involved in glomerular injury, ${ }^{11}$ there is still a need for a spontaneous model of diabetic nephropathy exhibiting more pronounced changes and bearing closer resemblance to what is seen in diabetic humans. It is worth stressing that diabetic SHR/N-cp are severly obese. Obesity is a potent risk factor for progression of renal diseases. ${ }^{12}$ There is growing evidence that the adipose tissue has a local renin-angiotensin system $^{13}$ and generates biologically active substances with systemic action, for example, leptin, adiponectin, etc. ${ }^{14}$ Leptin stimulates endocapillary proliferation, mesangial collagen deposition, proliferation of endothelial cells, increases TGF- $\beta$ expression $^{15}$ and stimulates also sympathetic nervous activity $^{16}$ which contributes to renal damage. ${ }^{17}$

It was the purpose of the present study to compare renal structure in the conventional STZ model with the model of the SHR/N-cp rat. The different types of glomerular cells were quantitated; glomerular, tubulointerstitial and vascular lesions were assessed using a score system and in addition further analyses by immunohistochemistry and electron microscopy were performed.

\section{Material and methods}

\section{Animals}

\section{STZ model of type I diabetes}

Streptozotocin (STZ) induced diabetes: male Sprague-Dawley rats (Charles River, Germany, mean body weight: $176 \pm 19$. $8 \mathrm{~g}$ ) were housed at constant room temperature $\left(21^{\circ} \mathrm{C}\right)$ and humidity $(75 \%)$ and exposed to a $12 \mathrm{~h}$ light and $12 \mathrm{~h}$ dark cycle. The animals had free access to water and standard rat pellets (Altromin 1324, Lage/Lippe, Germany). Experimental diabetes was induced by i.v. injection of $65 \mathrm{mg}$ Streptozotocin (Sigma Aldrich Chemie GmbH, Deisenhofen, Germany). Hyperglycaemia developed in injected animals on day 2 after STZ administration. Diabetic animals were treated daily with $4.1 \pm 1.4 \mathrm{IU} / \mathrm{kg}$ body weight (bw) long-acting human insulin (Insulin Ultratard ${ }^{\odot} \mathrm{HM}$, Aventis, Frankfurt/Main, Germany, $40 \mathrm{IU} / \mathrm{ml}$ ).

All animals were allowed free access to Standard Purina diet (chow \#5012, Purina Mills, St Louis, MO, USA).
SHR/N-cp model of type II diabetes

The spontaneously hypertensive obese rat (SHR/Ncp) is a model of type II diabetes model..$^{18}$ This strain resulted from mating Koletzky rats (which are obese) with SHR rats (which are hypertensive). The resultant progeny are either lean or obese and either normotensive or mildly hypertensive. The rats inherit obesity as an autosomal recessive trait. Since corpulent rats do not reproduce, the rats are bred by mating of heterozygotes. Mating yields three genotypes but only two phenotypes, that is, homozygous (cp/cp) corpulent and heterozygous $(\mathrm{cp} /+)$ and homozygous $(+/+)$ lean rats, in a ratio of $1: 2: 1$.

Animals were obtained from Vasarr (animal center, New York, USA) and were housed with a standard light cycle (light $0800-2000 \mathrm{~h}$ daily), 40$70 \%$ relative humidity, and maintained at $22 \pm 1{ }^{\circ} \mathrm{C}$ in standard box cages. All animals were allowed free access to Standard Purina diet (chow \#5012, Purina Mills, St Louis, MO, USA).

\section{Experimental Protocol}

Food and water consumption were monitored daily. Body weight, blood glucose and blood pressure (bp, by tail plethysmography) were measured at regular intervals. After 6 months, animals were kept in metabolic cages for $24 \mathrm{~h}$ urine collection. Urinary albumin excretion was measured using a rat-specific sandwich ELISA system as described in detail elsewhere. ${ }^{19}$ After 6 months, the experiment was terminated by retrograde aortic perfusion with glutaraldehyde or ice-cold $\mathrm{NaCl}$, respectively.

\section{Tissue Preparation}

The kidneys were taken out, weighed and dissected in a plane perpendicular to the interpolar axis, yielding slices of $1 \mathrm{~mm}$ width. In total, 10 small pieces of one kidney were selected by area weighted sampling for embedding in Epon-Araldite. Semithin $(1 \mu \mathrm{m})$ were prepared and stained with methylene blue and basic fuchsin. The remaining tissue slices were embedded in paraffin; $4 \mu \mathrm{m}$ sections were prepared and stained with hematoxylin/eosin (HE) and PAS. For immunohistological investigations, one half of the kidney was fixed in $8 \%$ buffered formaldehyde, embedded in paraffin and cut into $4 \mu \mathrm{m}$ thick sections. Paraffin sections were prepared and were incubated with the following antibodies using the avidin-biotin method: PCNA (proliferating cell nuclear antigen; $\alpha$-PCNA monoclonal mouse, Immunotech, Marseille, France), P27 ${ }^{\mathrm{KIP} 1}(\alpha-$ P27 polyclonal rabbit, Santa Cruz, CA, USA), TGF$\beta_{1}$ (anti-TGF- $\beta_{1}$, rabbit polyclonal IgG, Santa Cruz Biotechnology, Santa Cruz, CA, USA) and desmin $(\alpha$-desmin monoclonal mouse, Capinteria, CA, USA). Thick cryostat sections $(5 \mu \mathrm{m})$ were prepared 
and the sections were incubated with the following antibodies using the avidin-biotin method: $:^{20}$ fibronectin ( $\alpha$-fibronectin polyclonal rabbit, Sigma-Aldrich Chemie GmbH, Steinheim, Germany), endothelin ( $\alpha$-ET-1 polyclonal rabbit, Biotrend, Cologne, Germany) and PDGF-AB (platelet-derived growth factor; $\alpha$-PDGF-AB polyclonal goat, Upstate Biotechnology Inc., Waltham, USA). Optimal staining concentration was evaluated testing different dilution series. The following dilutions of antibodies were used: PCNA 1:150, desmin 1:50, TGF- $\beta$ 1:300, ET-1 1:25, fibronectin 1:150 and PDGF 1:50.

To avoid nonspecific cross-reactions of tissue components with antibody, a biotin-streptavidin detection system (biotin-streptavidin super sensitive; BioGenex, San Ramon, CA, USA) was selected. ${ }^{20}$ Negative controls were performed by omitting the primary antibody.

\section{Morphological Investigations}

Indices of renal damage (glomerulosclerosis, tubulointerstitial and vascular damage)

The degree of sclerosis within the glomerular tuft as an index of progression was determined on PASstained paraffin sections adopting the semiquantitative scoring system proposed by el Nahas et al. ${ }^{21}$ Using light microscopy at a magnification of $\times 400$, the glomerular score of each animal was derived as the mean of 100 glomeruli. The severity of glomerulosclerosis was expressed on an arbitrary scale from 0 to 4 as described in detail. ${ }^{20}$ Tubulointerstitial and vascular damage was assessed on PASstained paraffin sections at a magnification of $\times 100$ using a similar scoring systems as described in detail. $^{20,22}$

\section{Glomerular geometry}

Briefly, glomerular geometry was analyzed as follows: Volume density $\left(V_{\mathrm{v}}\right)$ of glomeruli and area density of glomerular tuft $\left(A_{\mathrm{AT}}\right)$ were measured by point counting according to $P_{\mathrm{P}}=A_{\mathrm{A}}=V_{\mathrm{V}}$ at a magnification of $\times 400$ on HE sections. ${ }^{23}$ The total area of glomerular tuft $\left(A_{\mathrm{T}}\right)$ was then determined as $A_{\mathrm{T}}=A_{\mathrm{AT}} \times A_{\text {cortex }}$. The number of glomeruli per volume $\left(N_{\mathrm{V}}\right)$ and the volume density $\left(V_{\mathrm{V}}\right)$ of glomeruli was obtained using the formula: $N_{\mathrm{V}}=k /$ $\beta \times N_{\mathrm{A}}^{1.5} / V_{\mathrm{V}}^{0.5}$ with $k=1.1$ and $\beta=1.382$. The total number of glomeruli was derived from the total volume of the renal cortex and the number of glomeruli per cortex volume: $N_{\text {glom }}=N_{\mathrm{V}} \times V_{\text {cortex }}$. The mean glomerular tuft volume was determined according to $v=\beta / k \times A_{\mathrm{T}}^{1.5}$ with $\beta=1.382$ and $k=1.1 .^{23}$

\section{Analysis of glomerular capillarization and cellular- ity on semithin sections \\ On five semithin sections per animal, glomerular capillarization and cellularity was analyzed using}

the point counting method and a 100 point eyepiece (Integrationplatte II, Zeiss Co.) at a magnification of 1000 (oil immersion) as described. ${ }^{24}$ Briefly, the length density $\left(L_{V}\right)$ of glomerular capillaries was determined according to the standard stereological formula, $L_{\mathrm{V}}=2 Q_{\mathrm{A}}$ (with $Q_{\mathrm{A}}$ being the number of capillary transects per area of the capillary tuft). Total length of glomerular capillaries per kidney ( $\left.L_{\text {total }}\right)$ was then derived from $L_{\mathrm{V}}$ and the total glomerular volume $\left(V_{\text {glom }}\right)$ with $V_{\text {glom }}=V_{\text {vglom }} \times V_{\text {cortex }}$. Glomerular cellularity (podocytes, mesangial and endothelial cells) was calculated in at least 30 glomeruli per animal from cell density per volume $\left(N \mathrm{C}_{\mathrm{v}}\right)$ and volume density of the cell type $\left(V_{\mathrm{C}_{\mathrm{v}}}\right)$ according to the equation: $N \mathrm{C}_{\mathrm{v}}=\mathrm{k} / \beta \times N \mathrm{C}_{\mathrm{A}}^{1.5} / V_{\mathrm{C}_{\mathrm{v}}}^{0.5}$ with $\beta$ for podocytes $=1.5$ and for mesangial and endothelial cells $=1.4$ and $k=1 .{ }^{24}$ The respective mean cell volume was calculated with $V_{\mathrm{c}}=$ $V \mathrm{c}_{\mathrm{v}} \times V_{\text {glom }}$.

\section{Electron microscopy}

In two randomly selected animals per group, ultrathin sections were qualitatively investigated using a Zeiss EM 10 (Zeiss, Oberkochen, Germany) at various magnifications. The glomerular basement membrane (GBM) was measured from the electron micrographs at $\times 6000$ and $\times 8000$ magnification. The GBM was recorded at 20 different randomly selected sites in five animals per group. ${ }^{25}$

\section{Immunohistological investigations}

Immunohistochemical staining for PCNA was examined using light microscopy at a magnification of $\times 400$. In 50 glomeruli per kidney, the number of PCNA-positive cells per glomerulus as well as per glomerular and per tubulointerstitial area were counted. Immunohistological stains using antibodies against TGF- $\beta_{1}$, ET-1, fibronectin and PDGF were analyzed by two investigators blinded with respect to the animal group and scored as described in detail elsewhere. ${ }^{20}$ For analysis of desmin immunohistochemistry, the capillary tuft was divided into four quarters and the following scoring system was used: score 0: no expression, score 1: desmin-positive cells in one-quarter, score 2: desmin-positive cells in two-quarters, score 3: desminpositive cells in three-quarters and score 4: desminpositive cells all over the capillary tuft. The damage score was then calculated as: $[(0-$ score 0$)+$ score $1+$ score $2+$ score $3+$ score 4 ]: $5+15$.

\section{TUNEL technique}

Investigation of apoptotic cells was performed with the TUNEL technique and a special kit (ApopTag ${ }^{\circledR}$ In Situ Apoptosis Detection Kit, Chemicon International, Temecula, CA, USA). Expression was investigated with Fast Red for conventional light microscopy (nuclear staining: hematoxylin/eosin). In 50 glomeruli per kidney, the number of TUNELpositive cells per glomerulus as well as per 
tubulointerstitial area were counted (light microscopy at a magnification of $\times 400$ ).

\section{Statistics}

For each diabetic rat strain and the nondiabetic control, data are given as mean \pm s.d. by one-way ANOVA, followed by unpaired $t$-test or MannWhitney $U$ test. The results were considered significant when the probability of error $(p)$ was less than 0.05. The difference between STZ and SHR/N-cp rat model was tested by Duncan's multiple-range test. The results were considered significant when the probability of error $(p)$ was less than 0.05 .

\section{Results}

\section{Systolic BP (Table 1)}

After 6 months, the systolic bp was not different between diabetic STZ animals compared to nondiabetic controls. There was also no significant difference between lean and obese SHR/N-cp animals. In contrast, blood pressure was significantly higher in SHR/N-cp compared to STZ diabetic rats.

\section{Urinary Albumin Excretion (Table 1)}

Urinary albumin excretion was significantly higher in diabetic STZ and SHR/N-cp animals compared to nondiabetic controls. Albuminuria was significantly higher in diabetic SHR/N-cp rats compared to diabetic STZ rats.

\section{Blood Chemistry (Table 2)}

There was no difference in serum creatinine between the experimental groups of both models. Urea concentration was elevated in diabetic STZ compared to their nondiabetic controls, but no difference was found between SHR/N-cp and lean controls. No difference of cholesterol concentrations was seen between STZ and controls, but diabetic SHR/N-cp rats had markedly higher cholesterol and triglyceride concentrations compared to lean controls.

\section{Morphological Investigations}

Indices of renal damage (Tables 3 and 4, Figure 1) Compared to nondiabetic control rats, only modest glomerular lesions were noted in STZ rats (Figure 1a and b): glomerular capillaries were irregular, widened and attached to the Bowman's capsule. Furthermore, mesangial cell number was slightly higher in STZ. Some expansion of the mesangial matrix was also noted (data not given). The degree of tubulointerstitial damage was modest. There were only few widened tubuli with incipient atrophy of the epithelial cells. In addition, slight focal interstitial fibrosis was observed. Intrarenal arterial vessel showed modest thickening of the walls.

In contrast, in the diabetic $S H R / N-c p$ rats marked mesangial sclerosis, occasionally with incipient nodule formation, was noted compared to lean SHR/N-cp controls (Figure 1c and d). Mesangial expansion, diffuse thickening of the capillary basement membrane and adhesions between adjacent loops as well as between loops and the parietal layer

Table 1 Animal data

\begin{tabular}{|c|c|c|c|c|c|}
\hline & $\begin{array}{c}\text { Body weight } \\
(\mathrm{g})\end{array}$ & $\begin{array}{l}\text { Systolic bp } \\
(\mathrm{mmHg})\end{array}$ & $\begin{array}{l}\text { Albumin excretion } \\
(\mathrm{mg} / 24 \mathrm{~h})\end{array}$ & $\begin{array}{l}\text { Blood glucose } \\
\quad(\mathrm{mg} / \mathrm{dl})\end{array}$ & $\begin{array}{l}\text { Leptin } \\
\text { (ng/ml) }\end{array}$ \\
\hline Nondiabetic SD $(n=10)$ & $521 \pm 52$ & $114 \pm 13$ & $0.5 \pm 0.2$ & $206 \pm 47$ & $2.17 \pm 1.01$ \\
\hline STZ-induced diabetes in SD $(n=8)$ & $301 \pm 52 *$ & $123 \pm 16$ & $1.4 \pm 0.5^{*}$ & $650 \pm 104$ & $0.29 \pm 0.15^{*}$ \\
\hline Nondiabetic lean SHR/N-cp $(n=9)$ & $489 \pm 41$ & $149 \pm 36$ & $33 \pm 14$ & $99 \pm 5$ & $1.31 \pm 0.59$ \\
\hline Diabetic obese SHR/N-cp $(n=8)$ & $660 \pm 68^{* * * * * *}$ & $143 \pm 26^{* * *}$ & $176 \pm 77^{* *, * * *}$ & $378 \pm 59$ & $27.9 \pm 14.4^{* *, * * *}$ \\
\hline
\end{tabular}

${ }^{*} P<0.05$ diabetic STZ vs control Sprague-Dawley (SD).

${ }^{*} P<0.05$ diabetic SHR/N-cp vs lean control.

${ }^{* * *} P<0.05$ diabetic SHR/N-cp vs STZ diabetes.

Table 2 Blood chemistry

\begin{tabular}{lcccccc}
\hline & $\begin{array}{c}\text { Creatinine } \\
(\mathrm{mg} / \mathrm{dl})\end{array}$ & $\begin{array}{c}\text { Urea } \\
(\mathrm{mg} / \mathrm{dl})\end{array}$ & $\begin{array}{c}\text { Cholesterol } \\
(\mathrm{mg} / \mathrm{dl})\end{array}$ & $\begin{array}{c}\text { Triglyceride } \\
(\mathrm{mg} / \mathrm{dl})\end{array}$ & $\begin{array}{c}\text { HDL-cholesterol } \\
(\mathrm{mg} / \mathrm{dl})\end{array}$ & $\begin{array}{c}\text { LDL-cholesterol } \\
(\mathrm{mg} / \mathrm{dl})\end{array}$ \\
\hline Nondiabetic SD $(n=10)$ & $0.64 \pm 0.08$ & $39.4 \pm 2.2$ & $90 \pm 19$ & $94 \pm 31$ & $63 \pm 12$ & $7.8 \pm 2.5$ \\
STZ-induced diabetes in SD $(n=8)$ & $0.65 \pm 0.23$ & $61.2 \pm 15.1^{*}$ & $115 \pm 13$ & $374 \pm 52^{*}$ & $55 \pm 19$ & $15.2 \pm 7.6$ \\
Nondiabetic lean SHR/N-cp $(n=9)$ & $0.72 \pm 0.14$ & $55 \pm 7.7$ & $75 \pm 11$ & $88 \pm 36$ & $13 \pm 1.3$ & $8.75 \pm 2.5$ \\
Diabetic obese SHR/N-cp $(n=8)$ & $0.82 \pm 0.24$ & $78 \pm 31.1$ & $150 \pm 43^{* *}$ & $1204 \pm 78^{* * * * *}$ & $441 \pm 43^{* * * * *}$ & $570 \pm 36^{* * * * *}$ \\
\hline
\end{tabular}

${ }^{*} P<0.05$ diabetic STZ vs control Sprague-Dawley (SD).

${ }^{*} P<0.05$ diabetic SHR/N-cp vs lean control.

${ }^{* *} \mathrm{P}<0.05$ diabetic SHR/N-cp vs STZ diabetes. 
Table 3 Renal damage indices (glomerulosclerosis index GSI, tubulointerstitial damage index TBI, vascular damage index VI) and glomerular geometry

\begin{tabular}{|c|c|c|c|c|c|}
\hline & GSI (score 0-4) & TBI (score 0-4) & VI (score $0-4)$ & $\begin{array}{l}\text { Mean glomerular } \\
\text { volume }\left(\times 10^{6} \mu \mathrm{m}^{3}\right)\end{array}$ & $\begin{array}{l}\text { Number of glomeruli } \\
\text { per one kidney }\end{array}$ \\
\hline $\begin{array}{l}\text { Nondiabetic } \\
\text { SD }(n=10)\end{array}$ & $0.06 \pm 0.01$ & $0.13 \pm 0.05$ & $0.02 \pm 0.01$ & $3.24 \pm 0.76$ & $40615 \pm 1143$ \\
\hline $\begin{array}{l}\text { STZ-induced } \\
\text { diabetes }(n=8)\end{array}$ & $0.23 \pm 0.1^{*}$ & $0.39 \pm 0.1$ & $0.37 \pm 0.4^{*}$ & $5.67 \pm 0.82^{*}$ & $39433 \pm 1665$ \\
\hline $\begin{array}{l}\text { Nondiabetic lean } \\
\text { SHR/N-cp }(n=9)\end{array}$ & $0.59 \pm 0.1$ & $0.25 \pm 0.13$ & $0.13 \pm 0.02$ & $4.34 \pm 0.31$ & $25966 \pm 4595$ \\
\hline $\begin{array}{l}\text { Diabetic obese } \\
\text { SHR/N-cp }(n=8)\end{array}$ & $1.94 \pm 0.01^{* *, * * *}$ & $2.93 \pm 0.15^{* * * * *}$ & $0.31 \pm 0.13^{* *}$ & $5.6 \pm 1.12$ & $20031 \pm 4063^{* *, * * *}$ \\
\hline
\end{tabular}

${ }^{*} P<0.05$ diabetic STZ vs control Sprague-Dawley (SD).

${ }^{*} P<0.05$ diabetic SHR/N-cp vs lean control.

${ }^{* * *} P<0.05$ diabetic SHR/N-cp vs STZ diabetes.

of Bowman's capsule were noted. Trapping of lipid droplets was observed within the capillaries and collagen deposition with hyalinization was also found. Compared to diabetic STZ rats, the glomerulosclerosis index (GSI) was higher in the diabetic SHR/N-cp.

Compared to lean SHR/N-cp rats in the diabetic SHR/N-cp (Figure 1 e and f), large numbers of protein casts were found within the tubular lumens, as well as fibrosis was observed with focal inflammatory infiltrates. The tubulointerstitial damage of the type II SHR/N-cp rats was much more marked than the lesions in diabetic STZ, but there was no difference in vascular damage between the diabetic models. Vascular damage was significantly higher in diabetic animals compared to their respective controls, but there was no significant damage between the models.

\section{Glomerular geometry (Table 3)}

The mean glomerular volume was consistently higher in the STZ compared to nondiabetic controls, as well as in diabetic SHR/N-cp compared to nondiabetic lean SHR/N-cp.

There was no significant difference in the number of glomeruli between STZ and their controls and between diabetic SHR/N-cp and nondiabetic lean SHR/N-cp, respectively. There was, however, a strikingly lower number of glomeruli per kidney in both lean and obese SHR/N-cp compared to STZ and their control animals.

\section{Glomerular cells and capillaries (Table 4)}

The mean number of podocytes per glomerulus was significantly lower in diabetic STZ rats than in their nondiabetic controls and mean podocyte volume was significantly higher. The mean number of mesangial and endothelial cells and the mesangial cell and endothelial cell volumes were significantly higher in diabetic STZ animals compared to nondiabetic controls. The length density of glomerular capillaries was lower in STZ rats compared to controls, reflecting capillary obliteration, but no difference in total length density was found between STZ and their nondiabetic controls.

The mean number of podocytes per glomerulus was also significantly lower in diabetic SHR/N-cp rats than in their nondiabetic controls and the mean podocyte volume was significantly higher in diabetic rats. The mean number of mesangial cells was significantly higher in diabetic obese animals compared to nondiabetic controls. In parallel, the mesangial cell volume was higher in diabetic SHR/ $\mathrm{N}-c p$ rats than in nondiabetic controls. In contrast, the number of endothelial cells was slightly, but significantly lower in the SHR/N-cp compared to their nondiabetic controls, but the mean endothelial cell volume was higher in diabetic animals compared to nondiabetic controls. The length density $\left(L_{\mathrm{v}}\right)$ and the total length density $\left(L_{\text {total }}\right)$ of glomerular capillaries were significantly lower in obese diabetic rats compared to nondiabetic controls.

There was no difference in podocyte and mesangial cell number between diabetic SHR/N-cp and diabetic STZ, but endothelial cell number was significantly lower in diabetic SHR/N-cp rats. The mean podocyte, mean mesangial and mean endothelial volume were significantly higher in diabetic SHR/N-cp rats compared to diabetic STZ rats.

Ultrastructural changes of the glomerulus (Figure 2) In diabetic STZ moderate, but significant $(P<0.05)$ thickening of the glomerular basement membrane $(222 \mathrm{~nm} \pm 64.8$. vs controls: $141.14 \mathrm{~nm} \pm 21.22)$ as well as diffuse mesangial matrix deposits were seen compared to nondiabetic Sprague-Dawley controls. In addition podocyte hypertrophy and degeneration of partial fusion of foot processes was seen (Figure 2).

In diabetic SHR/N-cp rats, in contrast, the lesions of the podocytes were much more pronounced. The basement membrane was significantly thicker compared to STZ animals (obese: $313.23 \mathrm{~nm} \pm 59.4$, lean: $217.4 \mathrm{~nm} \pm 54.7$ ). Podocytes volumes were excessive and podocytes further exhibited loss of foot 


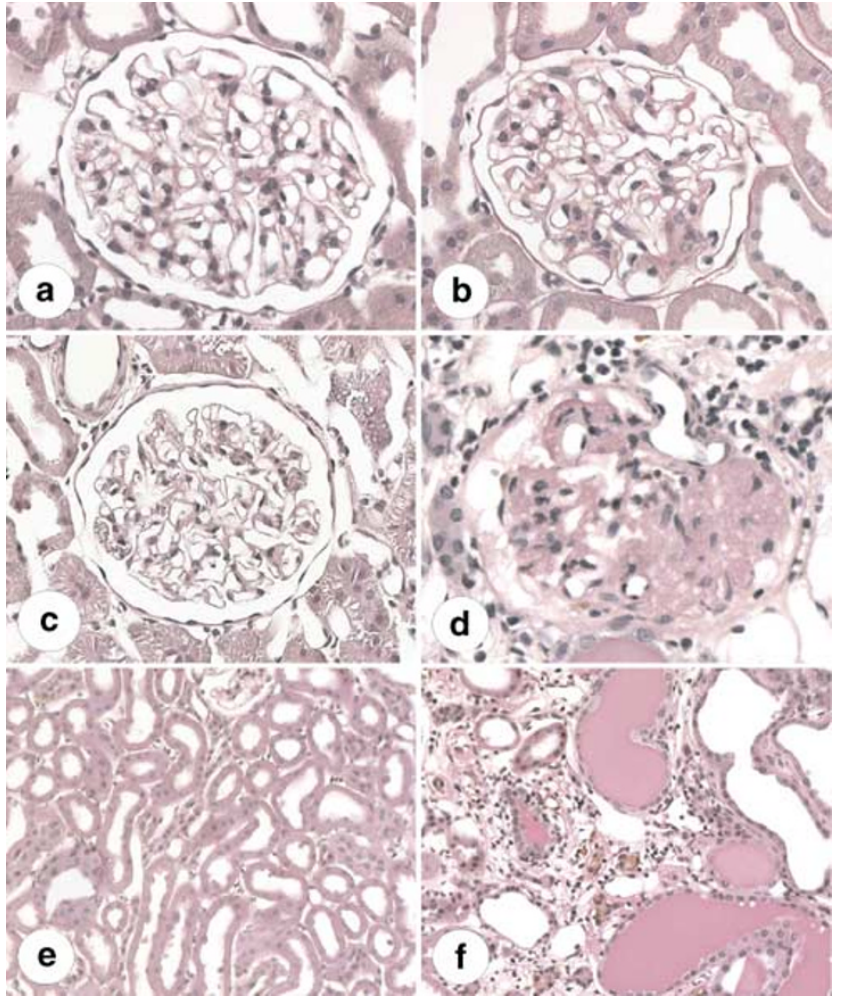

Figure 1 Glomerular morphology; light microscopy (magnification $\times 300$, HE staining): (a) normal glomerulus of a non-diabetic control rat; (b) glomerulus of a diabetic STZ rat with irregular capillaries, in part attached to Bowman's capsule and modest mesangial proliferation; (c) glomerulus of a lean SHR/N-cp rat with some irregular capillaries, but no tubulointerstitial lesion; (d) Glomerulus of an obese diabetic SHR/N-cp rat with irregular capillaries, many adhering to Bowman's capsule. Please note segmental aggregations of mesangial cells and matrix, creating the semblance of a nodule. Inflammatory infiltrate surround the glomerulus. Tubulointerstitial morphology; light microscopy (magnification $\times 200$, HE staining): (e) tubulointerstitial tissue of a nondiabetic lean SHR/N-cp rat with normal looking tubules. No interstitial infiltrate is visible; (f) tubulointerstitial tissue of a diabetic obese SHR/N-cp rat with distended tubuli, covered by atrophic epithelial cells and filled with protein casts. Notice increased inflammatory infiltrate surrounding the tubules.

processes and even cystic formation in the cytoplasma (Figure 2).

Immunhistological investigations (Figures 3-8)

PCNA: Proliferation and/or activation of glomerular and tubulointerstitial cells was assessed using an antibody against PCNA (Figures 3 and 4). Diabetic STZ animals had significantly more PCNA-positive cells per glomerular profile, mainly podocytes, than their nondiabetic controls. The number of PCNApositive tubulointerstitial cells per view field was significantly higher in diabetic STZ rats compared to nondiabetic controls.

Diabetic SHR/N-cp had significantly more PCNApositive cells per glomerular profile and tubulointerstitial view field than their nondiabetic controls (Figures 3 and 4). In diabetic obese SHR/N-cp, the number of PCNA-positive cells in the glomerulus was markedly higher compared to the STZ diabetic 


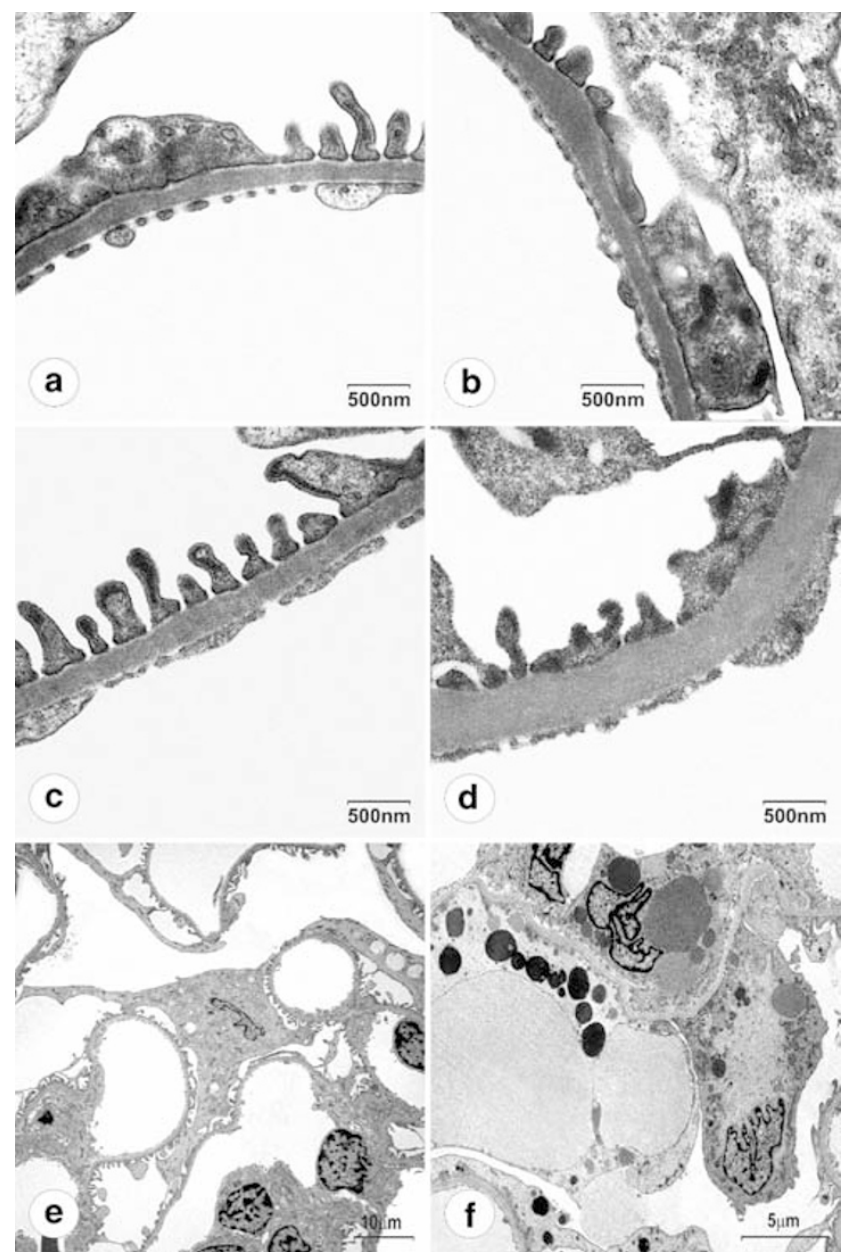

Figure 2 Glomerular ultrastructure in diabetic animals and controls (ultrathin sections, magnification: $\times$ 4000) (a) Basement membrane of a nondiabetic Sprague-Dawley control rat. (b) Fokal thickening of the basement membrane of a diabetic STZ rat. (c) Basement membrane of a nondiabetic lean rat with normal thickness. (d) Thickened basement membrane of an obese diabetic animal. The podocytes exhibit loss of foot processes. (e) Podocyte of a diabetic STZ rat with pseudocyst formation. (f) Hypertrophied podocyte of a diabetic SHR/N-cp rat with marked cystic transformation of the cytoplasma and loss of foot processes.

rats, while the number of PCNA-positive cells in the tubulointerstitial space was comparable.

TGF- $\beta$ : As shown in Figures 5 and 6 (in this and the following graphs please note the difference of scale of the ordinates), glomerular and tubulointerstitial TGF- $\beta_{1}$ protein expression was significantly higher in diabetic STZ rats than in controls. The glomerular and tubulointerstitial protein expression for TGF- $\beta_{1}$ was also higher in diabetic SHR/N-cp rats compared to their nondiabetic controls (Figures 5 and 6). Glomerular and tubulointerstitial protein expression for TGF- $\beta_{1}$ were significantly more marked in the diabetic SHR/N-cp compared to the STZ rats.

PDGF: On the protein level, PDGF-AB was expressed in mesangial and tubulointerstitial cells of untreated diabetic animals. The expression was significantly more pronounced in both diabetic models compared to their nondiabetic controls (Figure 5).

Diabetic SHR/N-cp rats showed significantly increased protein expression for PDGF compared to STZ rats.

ET-1 (Figures 5 and 7): ET-1 protein expression was more intense in glomerular cells in diabetic STZ animals compared to their nondiabetic controls. There was no significant difference in tubulointerstitial staining between diabetic STZ rats and nondiabetic control.

In contrast, protein expression for ET-1 was higher in glomerular and tubulointerstitial cells of diabetic SHR/N-cp rats compared to their nondiabetic lean controls (Figures 5 and 7). Tubulointerstitial but not glomerular expression of ET-1 was significantly higher in diabetic SHR/N-cp compared to STZ rats.

Fibronectin: Fibronectin expression (Figure 5) was significantly higher in the tubulointerstitium of STZ rats compared to Sprague-Dawley controls, but there was no difference in glomerular staining. In contrast, fibronectin expression was significantly increased in glomeruli in the diabetic SHR/N-cp rat compared to their nondiabetic controls.

There was no significant difference between diabetic SHR/N-cp and STZ rats.

Desmin: Desmin-positive podocytes were more frequent in diabetic STZ rats than in nondiabetic Sprague-Dawley controls (Figure 8). Similarly, the number of desmin-positive podocytes was markely higher in diabetic SHR/N-cp compared to lean nondiabetic controls.

The number of desmin-positive cells was also significantly higher in diabetic SHR/N-cp compared to diabetic STZ Sprague-Dawley rats.

Apoptosis: TUNEL staining demonstrated significant $(P<0.05)$ more glomerular- and tubulointerstitial-positive cells in diabetic STZ animals $(0.84 \pm 0.3$ cells per glomerulus, $7.6 \pm 1.7$ cells per viewfield tubulointerstitial tissue) compared to nondiabetic controls $(0.02 \pm 0.01$ cells per glomerulus, $0.52 \pm 0.07$ cells per viewfield tubulointerstitial tissue).

Obese diabetic SHR/N-cp rats (glomerular: $1.7 \pm 0.5$ cells per glomerulus, $24.4 \pm 14$. 3 per viewfield tubulointerstitial tissue) showed significantly more TUNEL-positive cells compared to lean nondiabetic rats $(0.1 \pm 0.1$ cells per glomerulus, $2.7 \pm 1.5$ per viewfield tubulointerstitial tissue).

\section{Discussion}

In our study in the STZ rat, only delicate glomerulosclerosis and modest tubulointerstitial lesions were found, so that morphological studies are problematic. The presumed target cell of hyperglycemia, the podocyte, was decreased in number and increased in volume. It also stained positive for PCNA and desmin, that is, indicators of podocyte distress. 
[PCNA-positive cells/ per glomeruli/ per VF tubulointerst.]

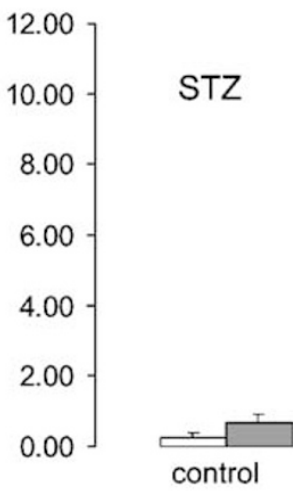

[PCNA-positive cells/ per glomeruli/ per VF tubulointerst.]

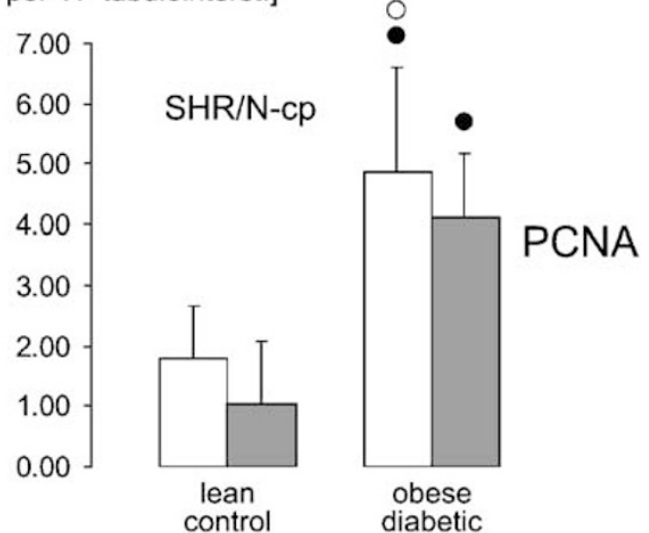

Figure 3 Expression of PCNA staining in glomerulus and tubulointerstitial space: $\square$ glomerular expression; $\square$ tubulointerstitial expression $P<0.05$ vs nondiabetic controls; $\bigcirc P<0.05$ SHR/N-cp vs STZ diabetes.

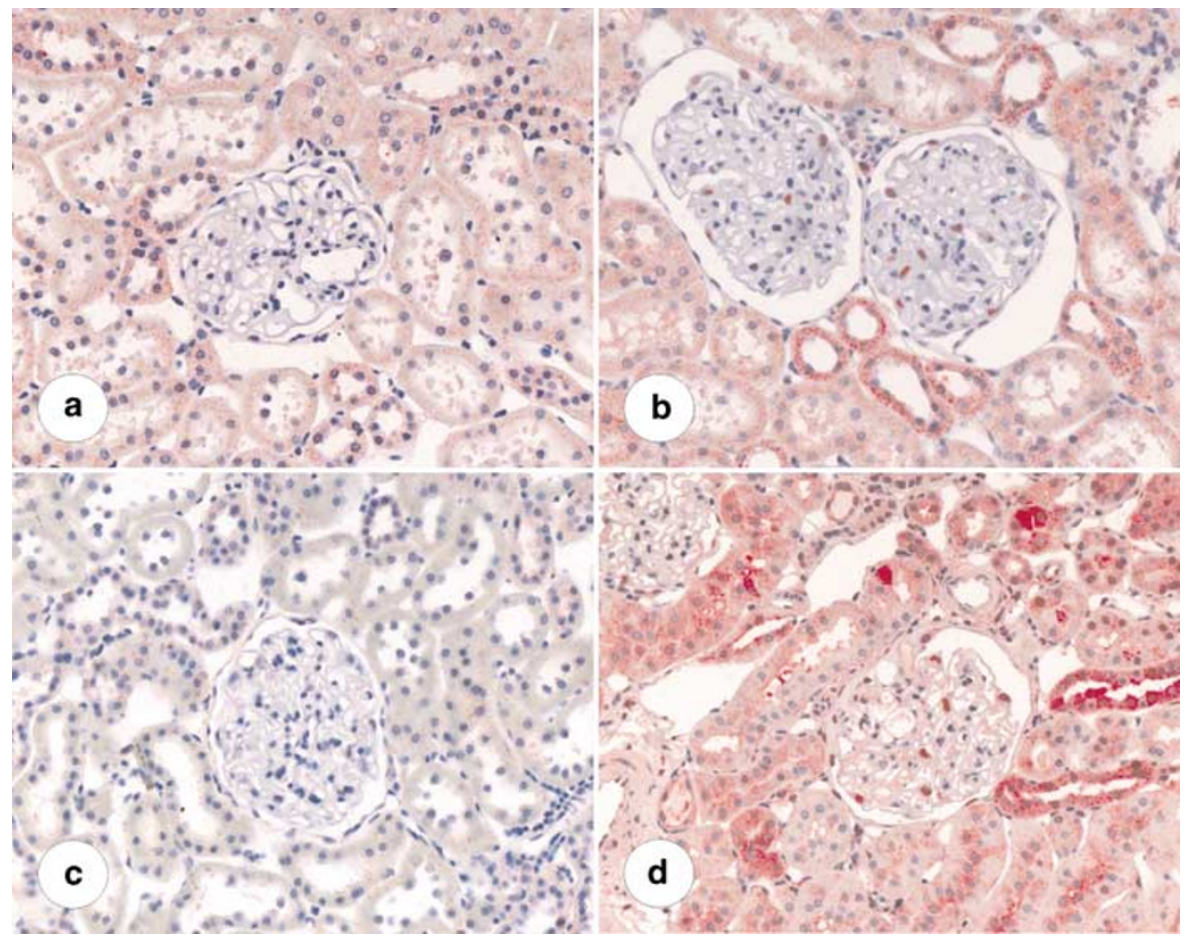

Figure 4 Glomerular expression of PCNA of type I and type II diabetic animals and controls (immunohistochemistry, magnification: 1:250). (a) Glomerulus of a control Sprague-Dawley rat with virtually no PCNA expression. (b) Glomerulus of a STZ type I rat with some PCNA + glomerular cells. (c) Glomerulus of a lean nondiabetic rat with virtually no PCNA expression. (d) Glomerulus of an obese diabetic SHR/N-cp rat with marked PCNA expression.

In sharp contrast to the modest changes in the STZ model, the lesions in the diabetic SHR/N-cp rat were marked. Particularly, pronounced glomerulosclerosis was seen bearing even some resemblance to Kimmelstiel-Wilson glomerulosclerosis. Staining for desmin and PCNA were more pronounced than in the STZ and the podocyte number was also strikingly reduced. In contrast to the STZ rat, the number of mesangial cells was not increased. It is uncertain whether this reflects less proliferation or cell loss by more vigorous apoptosis, what we could demonstrate in our study.

The importance of the genetic background for the development of glomerulosclerosis was noted by $\mathrm{He}$ et $a .^{26}$ who compared ROP (rodent model of retinopathy of prematurity) and C57 mice undergoing radiation injury. Glomerulosclerosis and severe glomerular enlargement was seen in sclerosisprone ROP, but not in C57 mice. 

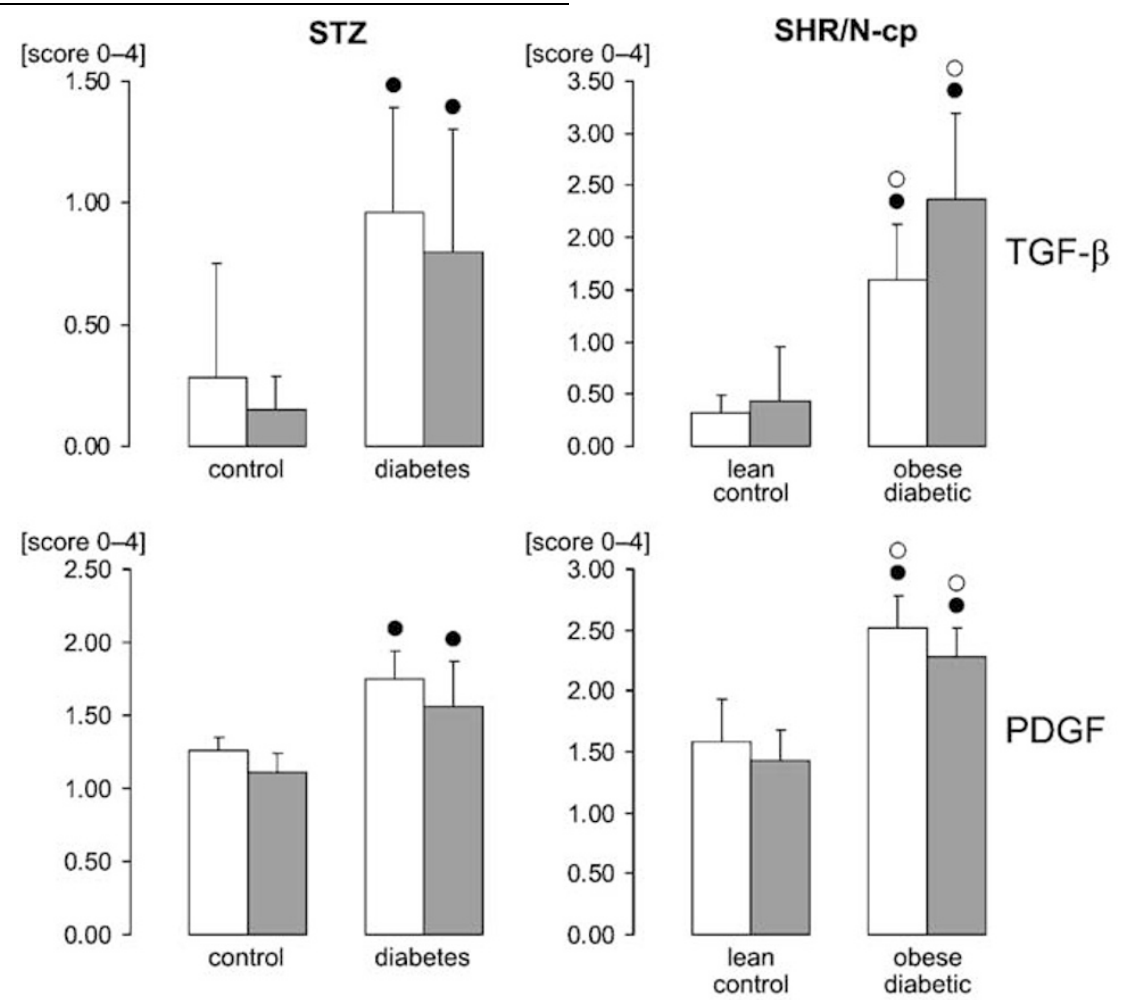

PDGF
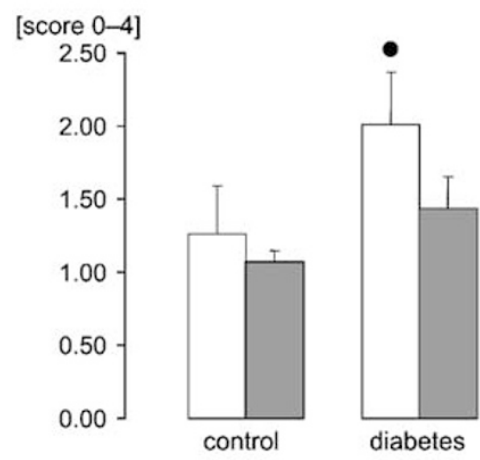

[score 0-4]
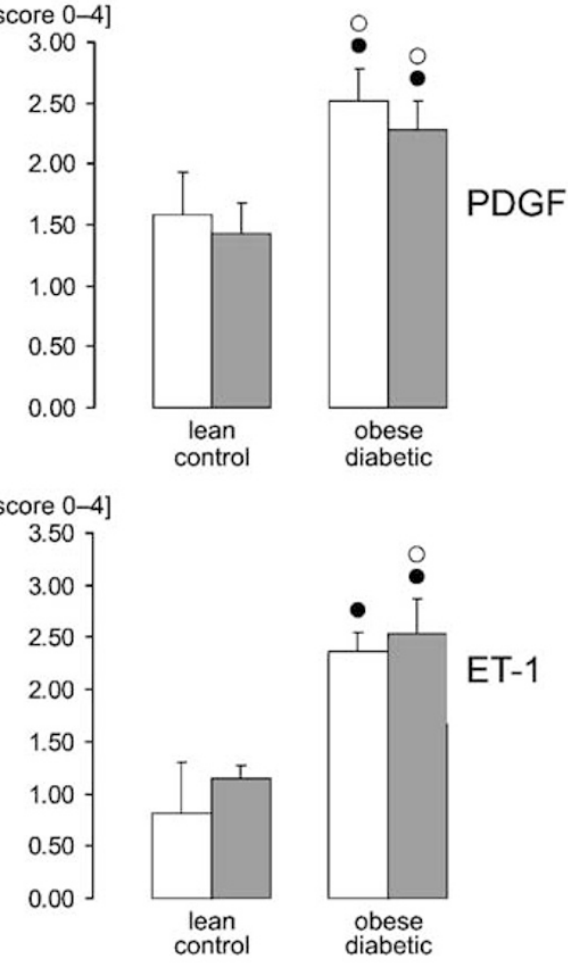

ET-1
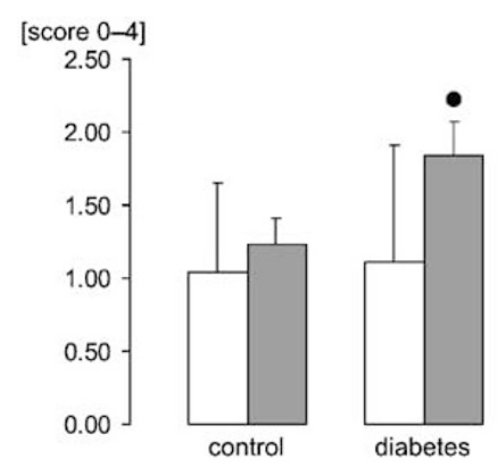

$\left.\begin{array}{r}\text { [score 0-4] } \\ 3.00 \\ 2.50 \\ 2.00 \\ 1.50 \\ 1.00 \\ 0.50 \\ 0.00\end{array}\right]$
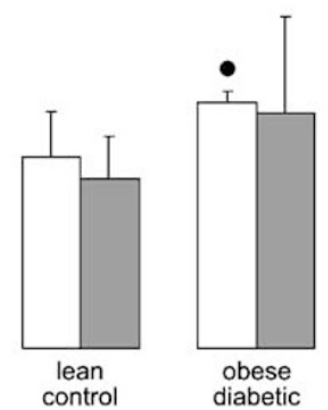

\section{Fibronectin}

Figure 5 Expression of TGF- $\beta_{1}$, PDGF-AB, ET-1 and fibronectin by immnohistochemistry: $\square$ glomerular expression; $\square$ tubulointerstitial expression. $P<0.05$ vs nondiabetic controls; $\bigcirc P<0.05$ SHR/N-cp vs STZ diabetes.

The potential importance of the number of glomeruli has recently been emphasized. ${ }^{27}$ The hypothesis has been advanced that "nephron underdosing, ${ }^{28}$ that is, a lesser number of glomeruli, predisposes to progressive renal damage. In this context it is of interest that in the nondiabetic SHR/
$\mathrm{N}-c p$, the number of glomeruli was lower than in the STZ.

The glomerular volume was higher in the SHR/Ncp, but was not different compared to lean SHR/Ncp controls. In the STZ, it was significantly higher compared to nondiabetic Sprague-Dawley controls. 

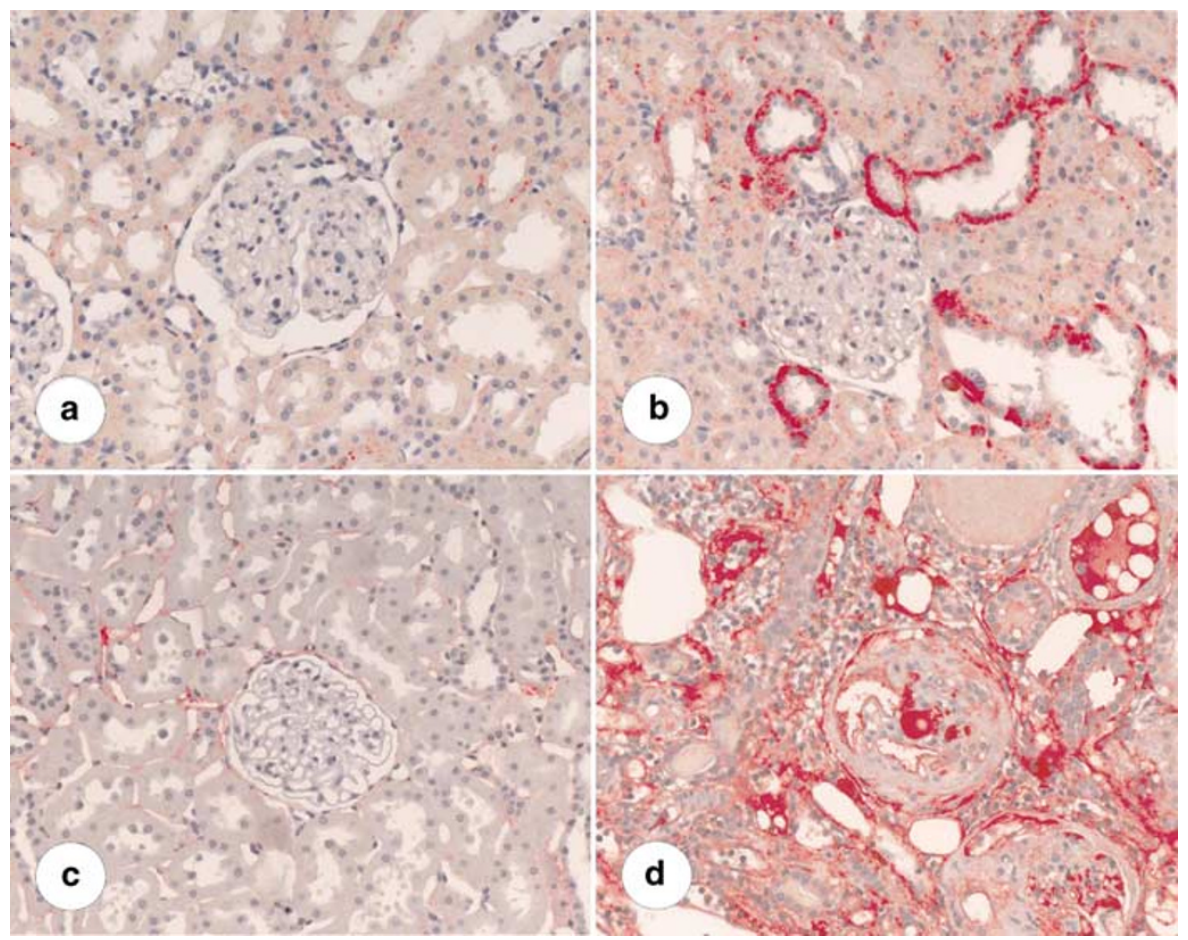

Figure 6 Glomerular and tubulointerstitial expression of TGF- $\beta$ in type I and type II diabetic animals and controls (immunohistochemistry, magnification: 1:250). (a) No TGF- $\beta$ protein expression of glomerulus and tubulointerstitium in Sprague-Dawley control rat. (b) Increased glomerular and tubulointerstitial TGF- $\beta$ protein expression in STZ type I diabetic rat. (c) Virtually no TGF- $\beta$ protein expression of glomerulus and tubulointerstitium in a lean nondiabetic rat. (d) Marked TGF- $\beta$ protein expression of glomerulus and tubulointerstitium in an obese diabetic type II animal.

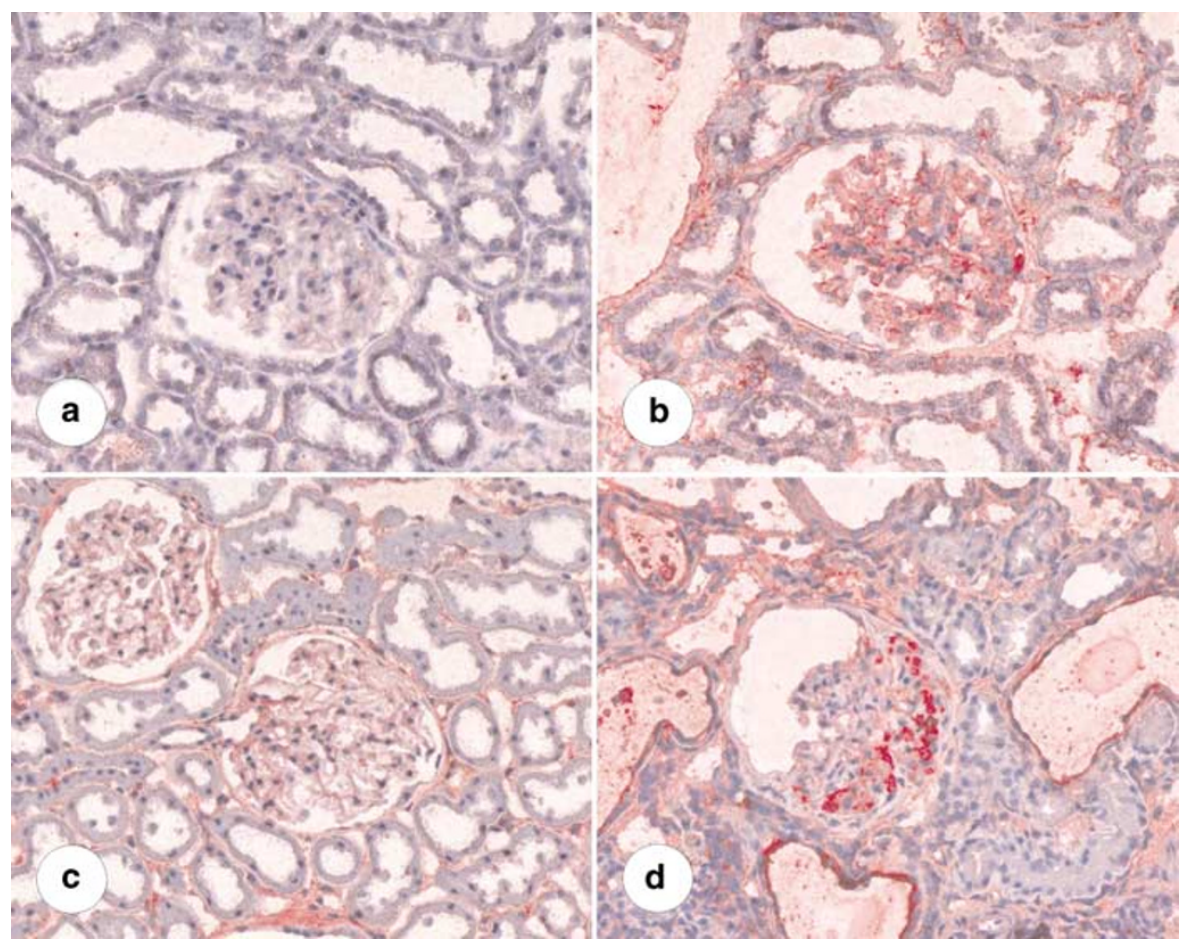

Figure 7 Glomerular and tubulointerstitial expression of ET-1 protein in type I and II diabetic animals and controls (immunohistochemistry, mag.: 1:250). (a) No ET-1 protein expression of glomerulus and tubulointerstitium in Sprague-Dawley control rat. (b) Increased ET-1 protein expression of glomerulus and tubulointerstitium in STZ type I diabetic rat. (c) Virtually no ET-1 protein expression of glomerulus and tubulointerstitium in a lean nondiabetic rat. (d) Marked ET-1 protein expression of glomerulus and tubulointerstitium in an obese diabetic type II animal. 
462
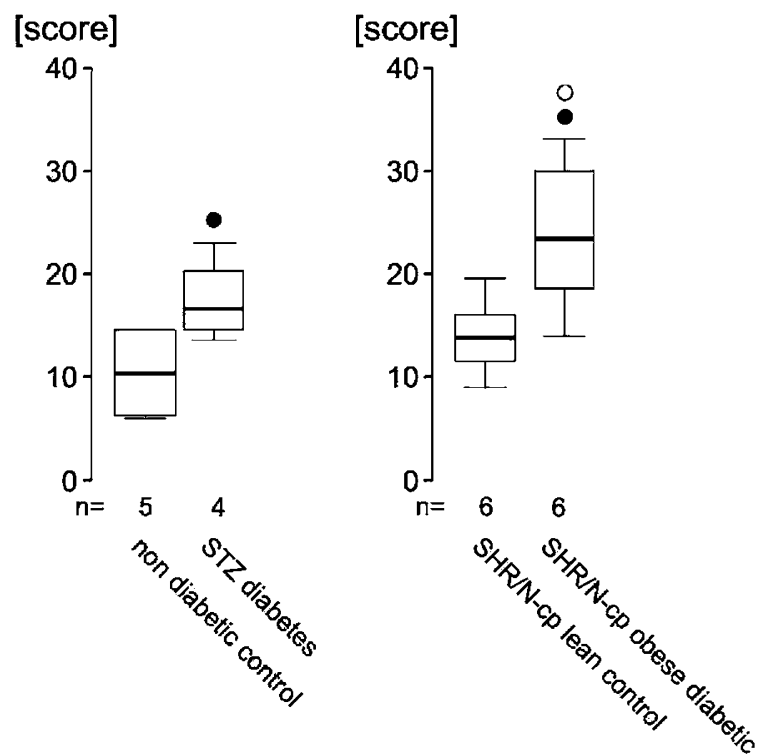

Figure 8 Expression of desmin in podocytes of STZ and SHR/Ncp rats compared to their respective controls, $P<0.05$ vs nondiabetic controls; $\bigcirc P<0.05$ SHR/N-cp vs STZ diabetes

This observation is of some interest, because the finding of increased glomerular volumes is less consistent in patients with type II as compared to patients with type I diabetes..$^{29-31}$ The number of the mesangial cells was significantly higher in STZ and SHR/N-cp rats, but the mean mesangial cell volume was considerably higher in the SHR/N-cp compared to the STZ rats. It is thought that the mesangial cell matrix production in culture correspond to a 'wound healing' phenotype. ${ }^{32}$ This hypothesis would be in line with our findings of increased expression of fibronectin.

Reduced capillary length density reflects loss of glomerular capillaries, that is, capillary obliteration. ${ }^{24}$ This value was significantly lower in the diabetic SHR/N-cp and in STZ rats compared to their respective controls. In parallel, the number of endothelial cells in the SHR/N-cp rat was decreased. Possibly as some kind of compensatory adaptation, endothelial cell volume increased much more in the SHR/N-cp than in the STZ rat. The cause of endothelial cell loss in diabetic SHR/N-cp is unknown, but it has been speculated that endothelial cell injury reduces the antithrombotic properties of the vessels and leads to capillary obliteration ${ }^{33}$ or apoptosis. ${ }^{34,35}$ The latter observation is inline with the finding that in the SHR/N-cp, the number of endothelial cells was lower and the endothelial cell volume higher.

The diabetic STZ rats showed only a minor increase in the tubulointerstitial damage index in contrast to pronounced increase in SHR/N-cp. The cause for the different reaction of the interstitium is unknown, but we point out that albuminuria was strikingly higher by a factor of 20 in the diabetic SHR/N-cp compared to STZ rat. TGF- $\beta$ that is also known to stimulate tubulointerstitial fibrosis ${ }^{36,37}$ was markedly expressed in the glomeruli and the tubulointerstitium of SHR/N-cp rats, much more so than in the STZ model. However, the role of TGF- $\beta$ is controversial: treatment with a neutralizing anti-TGF- $\beta$ antibody partially reversed basement membrane thickening and mesangial matrix expansion in the $\mathrm{db} / \mathrm{db}$ mouse. ${ }^{38}$ In contrast, anti-TGF- $\beta$ therapy failed to influence albuminuria in the same model. ${ }^{39}$

Although blood pressure was higher in the SHR/ $\mathrm{N}$-cp rat, the vascular damage index (VI) was not higher compared to STZ rats, despite strikingly higher concentrations of blood lipids than in the STZ rat.

To explain why the renal lesions are so much more pronounced in the diabetic SHR/N-cp rat, some considerations may be pertinent. First, the SHR/N-cp rats, both lean and obese, have higher blood pressures values than the Sprague-Dawley rat. For example, the normotensive Goto-Kakizaki rat model of diabetes exhibits only modest renal lesions, despite severe hyperglycemia. Superimposition of DOCA salt hypertension caused severe glomerular lesions in the same model. ${ }^{40}$ It appears that hyperglycemia sensitizes the kidney to blood pressure injury. SHR/N-cp rats do not exhibit particularly severe hyperglycemia, but substantially elevated plasma cholesterol and particularly triglyceride concentrations. According to numerous experimental ${ }^{41-43}$ and clinical observations, lipids, ${ }^{44}$ particularly oxidised lipids, ${ }^{45}$ cause glomerular injury. Finally, following the proposals of Brenner et $a l_{, 46,47}$ it is believed that a low number of glomeruli increases the risk of progression of renal disease. In this context it is of interest that the lean SHR/N-cp control, as well as the diabetic SHR/N-cp have a low number of glomeruli to begin with.

There is increasing evidence that obesity is a potent risk factor for progression. ${ }^{4-50}$ Our obese SHR/N cp rats had high plasma leptin concentration. In contrast, plasma leptin concentration in STZ-induced diabetes animals was low. It is conceivable that leptin is a potential progression promoter $^{51}$ in the SHR/N-cp rat.

\section{Conclusion}

The STZ model is still the work horse for animal experiments of diabetic nephropathy. The model is not satisfactory for morphological studies, since it exhibits only modest glomerulosclerosis and only minor tubulointerstitial damage and albuminuria. The diabetic SHR/N-cp model of type II diabetes presents much more striking glomerular and tubulointerstitial lesions combined with more pronounced albuminuria. It is therefore a promising model for research on the pathogenesis of diabetic nephropathy. 


\section{Acknowledgement}

A Koch and ML Gross were recipients of a grant in the Graduiertenkolleg 'Nieren- und Kreislaufregulation' of the Deutsche Forschungsgemeinschaft (DFG). M Adamczak has been supported by a Marie Curie Fellowship of the European Community programme: Improving the Human Research Potential and the Socio-economic knowledge base under contract number: HPMF-CT-2001-01501. Parts of the study were supported by grants of the Deutsche Forschungsgemeinschaft (SFB 423-B8), the University of Heidelberg (GR 83/97 and GR 133/00) and the DAAD (323-PPP Hungary). We thank the help of Dr S Orth and Dr G Miltenberger with animal experiments and perfusion. The skilled technical assistance of $\mathrm{H}$ Ziebart, M Weckbach, Z Antoni, G Gorsberg, S Söllner, M Klewer and P Rieger is gratefully acknowledged. Special thanks to H Derks, J Moyers and U Burkhard for graphic design and layout.

\section{References}

1 Ritz E, Orth SR. Nephropathy in patients with type 2 diabetes mellitus. N Engl J Med 1999;341:1127-1133.

2 Gambara V, Mecca G, Remuzzi G, et al. Heterogeneous nature of renal lesions in type II diabetes. J Am Soc Nephrol 1993;3:1458-1466.

3 Fioretto P, Mauer M, Brocco E, et al. Patterns of renal injury in NIDDM patients with microalbuminuria. Diabetologia 1996;39:1569-1576.

4 Gundersen HJ, Osterby R. Glomerular size and structure in diabetes mellitus. II. Late abnormalities. Diabetologia 1977;13:43-48.

5 Schmitz A, Gundersen HJ, Osterby R. Glomerular morphology by light microscopy in non-insulin-dependent diabetes mellitus. Lack of glomerular hypertrophy. Diabetes 1988;37:38-43.

6 Carpenter L, Cordery D, Biden TJ. Inhibition of protein kinase C delta protects rat INS-1 cells against interleukin-1beta and streptozotocin-induced apoptosis. Diabetes 2002;51:317-324.

7 Bendayan M. Immunocytochemical detection of advanced glycated end products in rat renal tissue as a function of age and diabetes. Kidney Int 1998;54: 438-447.

8 Girolami JP, Ouardani M, Bascands JL, et al. Comparison of B1 and B2 receptor activation on intracellular calcium, cell proliferation, and extracellular collagen secretion in mesangial cells from normal and diabetic rats. Can J Physiol Pharmacol 1995;73:848-853.

9 Boyd RB, Thompson VW, Atkin J. Alterations in glomerular permeability in streptozotocin-induced diabetic rats. J Am Podiatr Med Assoc 1996;86:57-62.

10 Mozaffari MS, Jirakulsomchok S, Wyss JM. Effects of simultaneous diabetes and hypertension in an insulin dependent diabetic model. Int J Exp Pathol 1991;72:655-664.

11 Isono M, Chen S, Hong SW, et al. Smad pathway is activated in the diabetic mouse kidney and Smad3 mediates TGF-beta-induced fibronectin in mesangial cells. Biochem Biophys Res Commun 2002;296: 1356-1365.
12 Shuldiner AR, Yang R, Gong DW. Resistin, obesity and insulin resistance-the emerging role of the adipocyte as an endocrine organ. N Engl J Med 2001; 345:1345-1346.

13 Massiera F, Bloch-Faure M, Ceiler D, et al. Adipose angiotensinogen is involved in adipose tissue growth and blood pressure regulation. Faseb J 2001;15:2727-2729.

14 Diamond Jr FB, Eichler DC. Leptin and the adipocyte endocrine system. Crit Rev Clin Lab Sci 2002;39: 499-525.

15 Han DC, Isono M, Chen S, et al. Leptin stimulates type I collagen production in $\mathrm{db} / \mathrm{db}$ mesangial cells: glucose uptake and TGF-beta type II receptor expression. Kidney Int Apr 2001;59:1315-1323.

16 Haynes WG, Morgan DA, Walsh SA, et al. Receptormediated regional sympathetic nerve activation by leptin. J Clin Invest 1997;100:270-278.

17 Amann K, Rump LC, Simonaviciene A, et al. Effects of low dose sympathetic inhibition on glomerulosclerosis and albuminuria in subtotally nephrectomized rats. J Am Soc Nephrol 2000;11:1469-1478.

18 Michaelis IV OE, Patrick DH, Hansen CT, et al. Insulinindependent diabetes mellitus (type II). Spontaneous hypertensive/NIH-corpulent rat. Am J Pathol 1986;123:398-400.

19 Schwarz U, Amann K, Orth SR, et al. Effect of 1,25 $(\mathrm{OH}) 2$ vitamin D3 on glomerulosclerosis in subtotally nephrectomized rats. Kidney Int 1998;53:1696-1705.

20 Gross ML, Ritz E, Schoof A, et al. Renal damage in the SHR/N-cp type 2 diabetes model: comparison of an angiotensin-converting enzyme inhibitor and endothelin receptor blocker. Lab Invest 2003;83:1267-1277.

21 el Nahas AM, Bassett AH, Cope GH, et al. Role of growth hormone in the development of experimental renal scarring. Kidney Int 1991;40:29-34.

22 Veniant M, Heudes D, Clozel JP, et al. Calcium blockade versus ACE inhibition in clipped and unclipped kidneys of $2 \mathrm{~K}-1 \mathrm{C}$ rats. Kidney Int 1994;46:421-429.

23 Weibel ER. Measuring through the microscope: development and evolution of stereological methods. J Microsc 1989;155(Part 3):393-403.

24 Amann K, Koch A, Hofstetter J, et al. Glomerulosclerosis and progression: effect of subantihypertensive doses of alpha and beta blockers. Kidney Int 2001;60:1309-1323.

25 Sagen JV, Bostad L, Njolstad PR, et al. Enlarged nephrons and severe nondiabetic nephropathy in hepatocyte nuclear factor-1beta (HNF-1beta) mutation carriers. Kidney Int 2003;64:793-800.

$26 \mathrm{He} \mathrm{C,} \mathrm{Esposito} \mathrm{C,} \mathrm{Phillips} \mathrm{C,} \mathrm{et} \mathrm{al.} \mathrm{Dissociation}$ of glomerular hypertrophy, cell proliferation, and glomerulosclerosis in mouse strains heterozygous for a mutation (Os) which induces a $50 \%$ reduction in nephron number. J Clin Invest 1996;97:1242-1249.

27 Fogo AB. Diabetic nephropathy: it's in the numbers. Kidney Int 2002;61:2274-2275.

28 Brenner BM, Milford EL. Nephron underdosing: a programmed cause of chronic renal allograft failure. Am J Kidney Dis 1993;21(5 Suppl 2):66-72.

29 Drummond K, Mauer M. The early natural history of nephropathy in type 1 diabetes: II. Early renal structural changes in type 1 diabetes. Diabetes 2002; 51:1580-1587.

30 Fioretto P, Steffes MW, Mauer M. Glomerular structure in nonproteinuric IDDM patients with various levels of albuminuria. Diabetes 1994;43:1358-1364. 
31 Taft JL, Nolan CJ, Yeung SP, et al. Clinical and histological correlations of decline in renal function in diabetic patients with proteinuria. Diabetes 1994;43:1046-1051.

32 Harris RC, Haralson MA, Badr KF. Continuous stretchrelaxation in culture alters rat mesangial cell morphology, growth characteristics, and metabolic activity. Lab Invest 1992;66:548-554.

33 Hoylaerts MF. Platelet-vessel wall interactions in thrombosis and restenosis role of von Willebrand factor. Verh K Acad Geneeskd Belg 1997;59:161-183.

34 Shimizu A, Kitamura H, Masuda Y, et al. Rare glomerular capillary regeneration and subsequent capillary regression with endothelial cell apoptosis in progressive glomerulonephritis. Am J Pathol 1997;151:1231-1239.

35 Kang DH, Anderson S, Kim YG, et al. Impaired angiogenesis in the aging kidney: vascular endothelial growth factor and thrombospondin-1 in renal disease. Am J Kidney Dis 2001;37:601-611.

36 Chen S, Hong SW, Iglesias-de la Cruz MC, et al. The key role of the transforming growth factor-beta system in the pathogenesis of diabetic nephropathy. Ren Fail 2001;23:471-481.

37 Wogensen L, Nielsen CB, Hjorth P, et al. Under control of the Ren-1c promoter, locally produced transforming growth factor-beta1 induces accumulation of glomerular extracellular matrix in transgenic mice. Diabetes 1999;48:182-192.

38 Chen S, Carmen Iglesias-de la Cruz M, Jim B, et al. Reversibility of established diabetic glomerulopathy by anti-TGF-beta antibodies in $\mathrm{db} / \mathrm{db}$ mice. Biochem Biophys Res Commun 2003;300:16-22.

39 Basile DP. Transforming growth factor-beta as a target for treatment in diabetic nephropathy. Am J Kidney Dis 2001;38:887-892.

40 Janssen U, Phillips AO, Floege J. Rodent models of nephropathy associated with type II diabetes. J Nephrol 1999;12:159-172.
41 Sugimoto K, Tsuruoka S, Fujimura A. Hyperlipidaemia and the progression of nephropathy in OLETF rats: effect of angiotensin-converting enzyme inhibitor, enalapril. Clin Exp Pharmacol Physiol 1999;26: 601-607.

42 Jandeleit-Dahm K, Cao Z, Cox AJ, et al. Role of hyperlipidemia in progressive renal disease: focus on diabetic nephropathy. Kidney Int Suppl 1999;71: S31-36.

43 Magil AB. Interstitial foam cells and oxidized lipoprotein in human glomerular disease. Mod Pathol 1999;12:33-40.

44 Kamanna VS, Roh DD, Kirschenbaum MA. Hyperlipidemia and kidney disease: concepts derived from histopathology and cell biology of the glomerulus. Histol Histopathol 1998;13:169-179.

45 Wanner C, Greiber S, Kramer-Guth A, et al. Lipids and progression of renal disease: role of modified low density lipoprotein and lipoprotein(a). Kidney Int Suppl 1997;63:S102-S106.

46 Fassi A, Sangalli F, Maffi R, et al. Progressive glomerular injury in the MWF rat is predicted by inborn nephron deficit. J Am Soc Nephrol 1998;9:1399-1406.

47 Brenner BM, Garcia DL, Anderson S. Glomeruli and blood pressure. Less of one, more the other? Am J Hypertens 1988;1(4 Part 1):335-347.

48 Klahr S, Morrissey J. Progression of chronic renal disease. Am J Kidney Dis 2003;41(3 Suppl 2): S3-S7.

49 Bonnet F, Deprele C, Sassolas A, et al. Excessive body weight as a new independent risk factor for clinical and pathological progression in primary IgA nephritis. Am J Kidney Dis 2001;37:720-727.

50 Kambham N, Markowitz GS, Valeri AM, et al. Obesityrelated glomerulopathy: an emerging epidemic. Kidney Int Apr 2001;59:1498-1509.

51 Wolf G, Chen S, Han DC, et al. Leptin and renal disease. Am J Kidney Dis 2002;39:1-11. 